\title{
Prevalence of Intestinal Helminthic Infection among School Children in Rural and Semi Urban Communities in Nigeria.
}

\author{
Dr. Lorina Ineta Emeka \\ Department of Microbiology, Faculty of Biological Sciences, University of Nigeria, Nsukka.
}

\begin{abstract}
The present study looks at the prevalence of soil transmitted helminths among school children from a rural and a semi urban setting at the Nsukka region of Enugu State of Nigeria. Stool samples were collected randomly and examined by basic parasitological techniques for the presence of intestinal helminths. 255 samples were collected and examined. Of these, 116(45.5\%) were infected with the results being statistically significant $(P<0.001)$. Ascaris lumbricoides was encountered in $46 \%$ of the infected specimens, hookworms in $23 \%$, Trichuris trichuira in 9\% and Strongyloides stercoralis in 11\%. Samples from the group 2 pupils who were from the rural setting had the highest prevalence in worm infestation and the results were statistically significant $(P<0.05)$. With respect to age, of the 4 age groups involved in the study, the 8-10 years were found to be the most infected in both groups with 100\% infection for the group 2 samples while the 14-16 were the least infected and the results are significant statistically.
\end{abstract}

Key Words: Helminthiasis, Intestinal helminths, Ascaris lumbricoides, hookworm, Trichuris trichuira, Strongyloides stercoralis.

\section{Introduction}

Soil transmitted helminthic infections are among the most common and neglected infections worldwide [1]. They are among the most prevalent afflictions of humans living in areas of poverty in the developing world. Two billion individuals were reported [2] to be parasitized with helminthic worms, majority of them living in resource-poor settings, $80 \%$ of these live in sub-Saharan Africa, [3, 2]. However, recent report by World Health Organisation [4] puts the figure at 880 million infected children who are in need of treatment. The African medical research foundation in 2007 [5] indicated that the young children particularly affected by intestinal helminths are from poor background, citing failure to use latrines as a major reason for the increase in the spread of parasitic helminthic worms. Epidemiological surveys have revealed that poor sanitary conditions such as defecation and faecal contamination of water bodies are the most important factors leading to intestinal worm infestation [6] while the spread is due to personal hygiene [7].

In Ethiopia, helminthic infections are the second most predominant causes of outpatient morbidity [8] and this according to Kumie and Ali [9] is because Ethiopia has one of the lowest qualities of drinking water and sewage coverage in the world. Children of pre-school and school age $(0-15 y e a r s)$ are the groups at risk of getting infected, [10,11, \& 12]. The effects of helminthic infection in children are adverse and alarming. Intestinal parasitic worms have detrimental effects on the survival, growth, general fitness and performance of school children according to reports by De Silva et al., [13] and WHO [14] These infections are known to trigger immune responses in man, creating problems for the body's ability to fight diseases, thus making affected individuals more prone to co-infection as was note by Watkin and Pollitt [15]. Reports by Borkow and Bentwich [16] indicated that helminthiasis is contributing to the unrelenting prevalence of AIDS and tuberculosis in many developing countries, particularly in Africa. Stunting of growth, iron deficiency, anaemia, rectal prolapsed and dysentery are features of intestinal helminths [17]. The burden of disease caused by helminthic parasitic worms globally is estimated to be 22.1 million disability adjusted life years (DALYs) lost to hookworm, 10.5 million to Ascaris lumbricoides, 6.4 million to Trichuris trichiura [18 \& 19].

Human intestinal Helminthiasis has been studied in Nigeria by various workers [20, 21, 22, 23, 24, 25 $\& 26]$ over the years. Some isolated helminths common in the region include Ascaris lumbricoides, the whipworm Trichuris trichuira, the hookworm Ancylostoma duodenale, Necator americanus and Strongyloides stercoralis. Periodic deworming of school children has also been instituted to curtail the problems caused by these worm infestations over the years and such programmes have been shown to improve growth and micronutrient status $[27,28]$. Availability of basic social and health amenities remains a major problem in Nigeria as in most third world countries therefore, the problem of worm infestation has persisted with Kirwan et al., [27] suggesting a less than four monthly treatment interventions but expressed the need to look for drug resistant strains. The present investigation was undertaken to compare two communities in one local government area in Nigeria with the view of looking at the prevalence of intestinal Helminthiasis in the region. 


\section{Materials And Methods}

\section{Study Area and Specimen collection.}

Samples were collected from school pupils attending the University of Nigeria, Nsukka staff clinic (Group 1) and pupils from Nkpor village (Group2) both of which are located in Nsukka local government area of Enugu State, Nigeria. Nsukka is located in South-eastern part of Nigeria and is characterized by poor environmental sanitation especially in areas with high density populations. Nsukka town is a university town with a mixed population, consisting of university student, university staff and a high population of public servant. Nkpor village however, is like any typical rural area village in Nigeria. It lacks the basic social amenities such as pipe borne water, regular electricity, proper medical facilities and good road networks. This village is also located in Nsukka local Government area of Nigeria. Unlike Nsukka town, Nkpor village population consist of mostly farmers and traders with very few civil servants. Both regions are characterized by two major seasons, the raining and dry seasons. The rainfall pattern of this area is moderate, lasting for a period of six months, with average atmospheric temperature of $20-30^{\circ \mathrm{C}}$.

Feacal samples were collected between January 2010 - April 2010 from school pupils attending the university of Nigeria Nsukka medical centre (Group 1) and Nkpor community health centre (Group 2). Wide mouthed bottles were given to the selected pupils, the bottles were labelled; their names, age and sex were recorded. Prior to sample collection, permission was obtained from both parents and hospital authority.

\section{Parasitological Examination of specimens}

Collected specimens were examined on the same day of collection. Parasitological examination was by the direct wet mount $[29,30]$ and the formol-ether concentration methods. For the wet mount, each stool specimen, was well mixed, 1gram emulsified in normal saline and stained with iodine for microscopic examination. For the formol-ether concentration method, [31, 32] sediments from each centrifuged specimens was placed on a slide and examined at x10 and x40 magnification [25]. Negative stool samples were confirmed through the formol-ether concentration method. The type of intestinal parasite seen was recorded.

\section{Statistical Analysis}

Microsoft excel (2010) chi test was used to compare the results. Using the $\chi^{2}$ tests from the contingency tables values were considered significant at $\mathrm{P}<0.05$.

\section{Results}

Two hundred and fifty five (255) samples were collected from both centres. Of these, 116 (45.5\%) were infected with various types of intestinal helminthic infections. The results are presented in table 1and are statistically significant $(\mathrm{P}<0.001)$. The encountered helminths were Ascaris Lumbricoides $(46 \%)$, Strongyloides stercoralis (11\%), Trichuris trichuira (9\%) and hook worm (23\%). Comparisons in the prevalence of these helminths from the two groups are shown in figure 1. The group 2 samples had the highest prevalence for $T$. Trichuira (7\%), S. stercoralis $(11 \%)$, and hookworm $(16 \%)$ and the difference between the two sites was statistically significant $(\mathrm{P}<0.05)$.

Four age groups, 5-7, 8-10, 11-13 and 14-16 years were included in the study. Helminthic parasitic infection was encountered in all the groups. The highest prevalence was among the 8-10 years of age group of which $88(76 \%)$ of the 116 positive specimens harboured various types of worms. The least infected were the 1416 years of age group with about $4 \%$ of them infected as shown in table 2 with the difference being statistically significant $(\mathrm{P}<0.001)$.

For group 1 samples, the results presented in table 3 shows that the 5-7 years age group had no intestinal helminths. Of the samples examined in the 8-10 years of age group, $40(83 \%)$ were found to be harbouring intestinal worms. The percentage of worm infestation was lower for the 11-13 and 14-16 years age group, at $8.3 \%$ for each group. The results are statistically significant $(\mathrm{P}<0.001)$. However, of the examined 12 samples in the 5-7 years age range of group 2, 8(11.76\%) were seen to be infested with intestinal helminthic infection. All the 8-10 years of age from this group were also infected with various types of worms. For the 1113years and the $14-16$ years percentage of infestation was low at $17.65 \%$ and $4.41 \%$ respectively. The results are shown in table 4 and they are statistically significant.

The results on helminths encountered in relation to gender are presented in figure 2. The figure shows that the incidence of occurrence of parasitic helminths was highest in males than in females. Strongyloides stercoralis was also seen in the group 2 male samples and complete absent in those from group 1. However, a comparison in the percentage infestation from the two groups shows the group 2 samples to be infected with all the encountered helminthic species (A. lumbricoides 13\%, S. stercoralis 11\%, T. Trichuira 7\% and hookworms $16 \%)$ as shown in figure 2 . However, the highest percentage (23\%) of A. lumbricoides infection was amongst the group 1 samples. 
Table 1: Prevalence of Intestinal Helminths among School Children Two centres in Nsukka area.

\begin{tabular}{|l|l|l|l|}
\hline Study area & Number examined & Number positive & Percentage positive \\
\hline Group 1 & 162 & 48 & \\
\hline Group 2 & 93 & 68 & $51.38 \%$ \\
\hline Total & 255 & 116 & $100 \%$ \\
\hline$\chi^{2}=15.9, \mathrm{DF}=1, \mathrm{P}=0.000, \mathrm{P}<0.001$ & & \\
\hline
\end{tabular}

Table 2: Age Distribution and Percentage (\%) Prevalence of Intestinal Helminths

\begin{tabular}{|l|l|l|l|}
\hline Age (years) & Number examined & Number Infected & $\begin{array}{l}\text { Percentage Infection } \\
(\%)\end{array}$ \\
\hline $\mathbf{5 - 7}$ & 24 & 8 & $7 \%$ \\
\hline $\mathbf{8 - 1 0}$ & 111 & 88 & $76 \%$ \\
\hline $\mathbf{1 1 - 1 3}$ & 63 & 16 & $13.8 \%$ \\
\hline $\mathbf{1 4 - 1 6}$ & 57 & 4 & $3.45 \%$ \\
\hline Total & 255 & 116 & $100 \%$ \\
\hline
\end{tabular}

$X^{2}=37.9$, Df $=3, \mathrm{P}=0.000 . \mathrm{P}<0.001$

Table 3: Intestinal Helminths distribution in relationship to age of Group 1 School Children.

\begin{tabular}{|l|l|l|l|}
\hline Age groups (years) & $\begin{array}{l}\text { Number } \\
\text { examined }\end{array}$ & $\begin{array}{l}\text { Number } \\
\text { Infected }\end{array}$ & $\begin{array}{l}\text { Percentage } \\
\text { Infected (\%) }\end{array}$ \\
\hline $\mathbf{5 - 7}$ & 12 & 0 & $0 \%$ \\
\hline $\mathbf{8 - 1 0}$ & 66 & 40 & $83.33 \%$ \\
\hline $\mathbf{1 1 - 1 3}$ & 45 & 4 & $8.33 \%$ \\
\hline $\mathbf{1 4 - 1 6}$ & 39 & 4 & $8.33 \%$ \\
\hline Total & 162 & 48 & $100 \%$ \\
\hline
\end{tabular}

$\chi^{2}=27.3, \mathrm{DF}=3, \mathrm{P}=0.000 . \mathrm{P}<0.001$

Table 4: Intestinal Helminths distribution in relationship to age of Group School Children

\begin{tabular}{|l|l|l|l|}
\hline Age groups (years) & Number examined & Number Infected & $\begin{array}{l}\text { Percentage Infected } \\
(\%)\end{array}$ \\
\hline $\mathbf{5 - 7}$ & 12 & 8 & $11.76 \%$ \\
\hline $\mathbf{8 - 1 0}$ & 45 & 45 & $66.18 \%$ \\
\hline $\mathbf{1 1 - 1 3}$ & 18 & & 12 \\
\hline $\mathbf{1 4 - 1 6}$ & 18 & 3 & $17.65 \%$ \\
\hline Total & 93 & 68 & $4.41 \%$ \\
\hline
\end{tabular}

$\chi^{2}=16.6, \mathrm{DF}=3, \mathrm{P}=0.001 . \mathrm{P}<0.001$ 
Figure 1: Prevalence of Intestinal Helminths from the two localities.

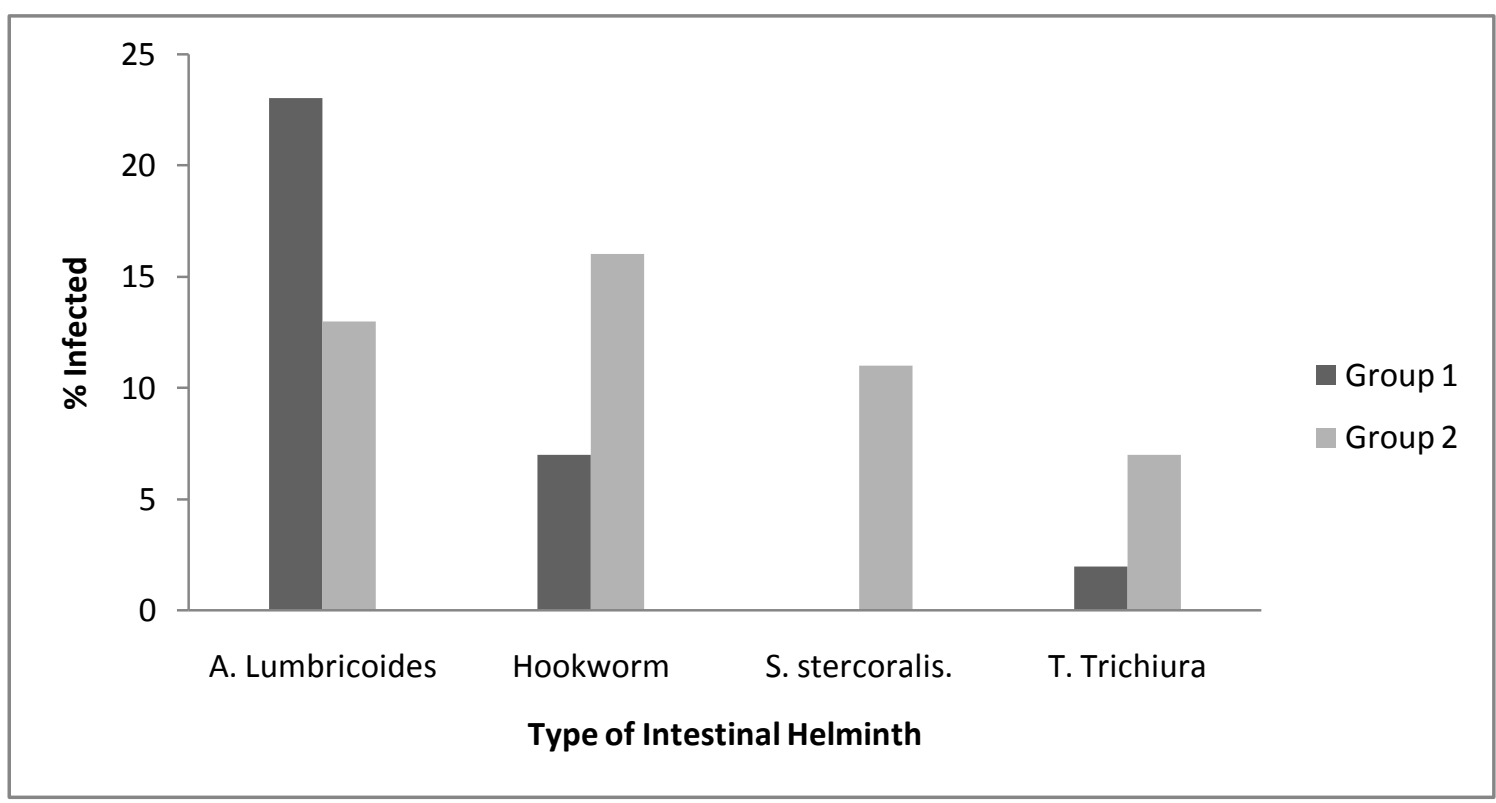

Figure2. Prevalence of Intestinal Helminths with regards to Gender

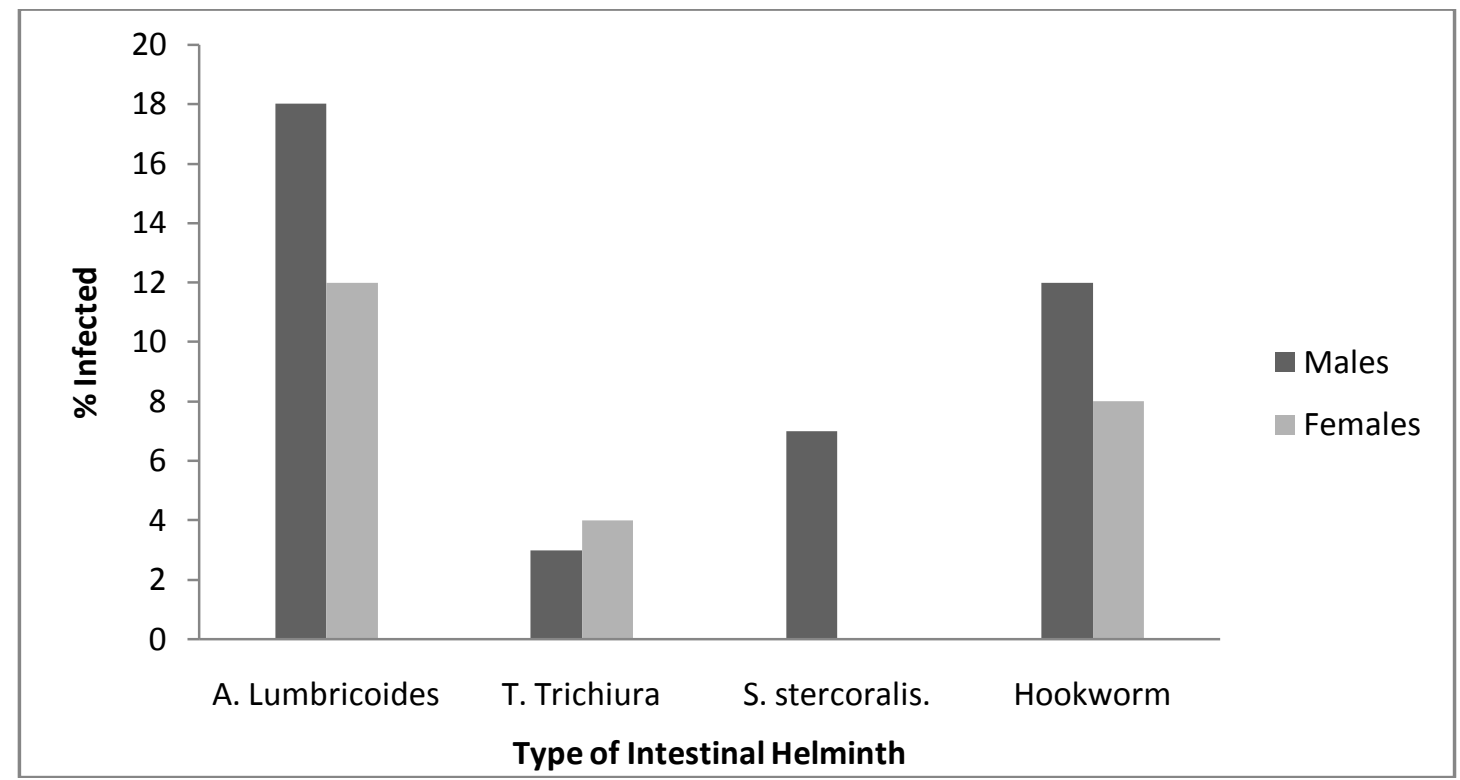

\section{Discussion}

Ascaris lumbricoides, Trichuris trichiura, Strongyloides stercoralis and hookworms are seen in the present study to be the prevalent intestinal parasitic helminths encountered. These worms were isolated from $116(45.5 \%)$ of the examined samples showing that these are the prevalent intestinal helminths in this region of Southeast of Nigeria. Similar findings had been reported by [33, 34, 27, \& 25]. Reports by Ekundayo et al., [35] indicated that since the 1970s, the triad of A. lumbricoides, T. Trichuira and hookworm species are common in Nigeria. While Akogun [36] had indicated that the prevalence of these parasites had not changed in the past 50 years especially with Ascaris. In the present investigation, with A. lumbricoides being a common feature in specimens from both groups, it can be said that helminthiasis remains a problem in Nigeria. The overall prevalence is high at $45.5 \%$. However, Damen et al., [26] reported an overall prevalence of $30.2 \%$ from their study in the North-Central Nigeria. The results obtained in this study shows A. lumbricoides to have the highest prevalence (45.5\%), followed by hookworm (23\%) and S. stercoralis (11\%); while the least prevalent was $T$. trichiura (9\%). These high percentages could mean that there hasn't been recent deworming programme in the region or there could be the possibility of having been re-infected after a period of deworming. There is therefore the need for urgent intervention. The pattern seen in the present investigation is consistent with 
findings by Adeyeba and Akinlabi [37] Ekpenyong and Eyo [25]. A percentage of prevalence as high as 45.5 in the present study, reflects that the poor unhygienic practices of school pupils has not changed with passage of time. These unhygienic practices keep enhancing the transmission of helminthic parasites over years. Concerns about the hygienic practices of people defecating, improper disposal of sanitary waste, lack of lavatories at home and public places had been expressed by Holland and Asaolu [38], Nwosu [39] as well as by Adeyeba and Dipeolu [40]. These findings show that despite the years of group deworming in schools, the problem of helminthiasis in Nigeria has persisted. That $T$. trichuira and hookworms were also encountered is not unexpected as similar conditions are known to affect the endemicity of these parasitic worms [41]. Also, according to Crompton [42], intestinal helminths are rarely found alone in human communities.

The results presented in table 2 shows that the group 2 stool samples had S. stercoralis. This species was absent in the samples from group 1. It could mean that there is a lot of walking bare footed among this group of pupils. The presence of S. stercoralis was reported by Ozumba and Ozumba [34] in their study. They were of the view that a large population of the inhabitants from their study area, walked barefooted since hookworm infection is contracted through skin penetration.

With helminthic infection as regards to age, table 2 shows that pupils between 8 and 10 years of age were the most infected. This might be because at this age, this group attend to their personal care with not much help from their parents. Also they are quite exposed to, much contact with soil contaminated with faeces. This is however contrary to the findings of Ozumba and Ozumba [34] who reported that the 12-17 teenagers had the highest rate of infection. They were of the view that this might have been as a result of outdoor activity of this age group. In the present study however, school pupils within the age range of 14-16, were found to be the least infected probably because at this age, education on the need for proper personal hygiene has been impacted and they are more conscious of their health than the other age groups. That some of them were infected could be attributed to outdoor activities as had been suggested by Ozumba and Ozumba [34]. The variance in pupils presenting themselves at the health centres were specimens for the study was collected could have been the reason for the differences obtained in the study.

Table 2 also shows that intestinal parasitic infection was low among pupils between 5-7 years of age in the present study. This is contrary to the findings of Ekpenyong and Eyo [25] who reported from their findings that children between the ages of 4 and 6 had the highest incidence of $A$. lumbricoides infection and explained this to be due to an under developed immunity to parasitic infection. It would however be expected that at the age of 5 to 7, parents still monitor and restrict the outdoor activities of this age group as well as being active in taking care of their personal hygiene. They probably do not go farming with their parent at this age thus not exposed to soil contaminated faeces. Again regional differences might be contributory factors to the differences. Gender wise, both males and female were infected with intestinal helminths suggesting equal exposure to infecting parasites. A comparisons in the percentage of infection for both sexes as shown in figure 2, shows the males to be more carriers of parasitic helminthic infections than the females. All the $S$. stercoralis encountered were from male samples. This can be attributed to the fact that male do participate in more outdoor activities than their female counterparts in this region, contrary to the findings of Ekpenyong and Eyo [25], who from their study, indicated that intestinal helminths infections were more common in females than in males. They [25] suggested that the prevalence of parasitic infections were sex dependant while an earlier report by Nairain [43] indicated that the differences could be related to the levels of exposure.

The present investigation has shown that intestinal helminthiasis remains a public health problem in Nigeria. The fact that the socio-economical facilities in Nigeria does not appear to have changed much over the years, couple with the advent of more healthcare demanding diseases such as AIDS/HIV, suggests the need for urgent new methods for the control of intestinal helminthiasis to avoid the problem of developing resistant strains. Economic development, proper education of parents and children, poverty eradication if possible would go a long way to curtail the menace of these parasitic helminths.

\section{References}

[1]. Peter JH, Paul JB, Jeffrey MB, Charles HK et al., (2008). Helminth Infections: the great neglected Tropical Diseases. The Journal of Clinical Investigation, 118(4): 1311-1321.

[2]. World health organization (2002). The prevention and control of schistosomiasis and soil transmitted Helminthiasis. Geneva: WHO; 2002.

[3]. Davis A, Cook C, Zumla A. (2003). Schistosomiasis: Manson's Tropical Diseases. London: Elsevier Science; 21 2003, 1431-1469.

[4]. World Health Organisation Report (2013). Intestinal worms.

[5]. African Medical and Research Foundation, (AMREF), 2007. The child Health Course, Unit 15: Common Problems of the newborn, pp 1-27.

[6]. Brooker S, Hotez PJ, Bundy DA (2008). Hookworm-Related Anaemia. Among Pregnant Women: A Systematic Review. PLoS. Negl. Trop. Dis. 2: e291.

[7]. Van Eijk AM, Lindblade KA, Odhiambo F (2009). Geohelminth Infections among Pregnant Women in Rural Western Kenya; a Cross-Sectional Study. PLoS Negl. Trop. Dis. 3: e370.

[8]. Alemu A, Atnafu A, Addis Z, Shiferaw Y. Alemu et al. (2011). Soil transmitted helminths and Schistosoma mansoni infections among school children in zarima town, northwest Ethiopia. BMC Infectious Diseases 11:189. 
[9]. Kumie A and Ali A (2005). An overview of environmental health status in Ethiopia with particular emphasis to its organization, drinking water and sanitation: a literature survey. Ethiop J Health Dev. 19(2):89-103.

[10]. Jarabo M, Garcia-Moran NP, Garcia-Moran JI (1995). Prevalence of intestinal parasites in a student population. Enferm Infecc Microbiol Clin. 13:464-468.

[11]. Fentiman A., Hall A.,Bundy D. (2001). Social Science and Medicine 52, 429-439.

[12]. Albonico M., Ramsan M., Wright V., Jape K., Haji HJ. Taylor M, Savioli L. and Bickle Q. (2002). Soil-transmitted nematode infections and mebendazole treatment in Mafia Island school children. Annals of Tropical Medicine and Parasitology, 96 : 717 726.

[13]. De Silva NR, Guyatt HL, Bundy DA (1997). Morbidity and mortality due to Ascaris-induced intestinal obstruction. Trans R Soc Trop Med Hyg. 91:31-36

[14]. WHO (1998). Diarrhoea, Reducing Mortality from Major Killers Of Children. World Health Report Revised September 1998, Fact Sheet No: 178

[15]. Watkins W.E. and Pollitt E. (1997), Psychological Bulletin 121 (2) 171-191.

[16]. Borkow G. and Bentwich Z. (2000). Bulletin of World Health Organization, 78(11).

[17]. Crompton DWT, Nesheim MC. (2002). Nutritional impact of intestinal helminthiasis during the human life cycle. Annual Review of Nutrition 22:35-59.

[18]. Chan MS. (1997). The global burden of intestinal nematode infections - Fifty years on. Parasitology Today 1997, 13(11):438-443.

[19]. Hotez PJ, Molyneux DH, Fenwick A, Ottesen E, Ehrlich Sachs S, and Sachs JD. (2006). Incorporating a rapid-impact package for neglected tropical diseases with programs for HIV/AIDS, tuberculosis, and malaria. PLoS Medicine 3(5):e102.

[20]. Obiamiwe BA. and Nworsi P. (1991). Human gastro-intestinal parasites in Bendel State, Nigeria. Angrew Parasitology, 32 : 177 183.

[21]. Awogun IA., Okwerekwu FE., Oyawoye OA. and Bello AB. (1995). Helminthic infections and anaemia among pregnant women attending antenatal clinic in Illorin, Nigeria. Biosciences Research Communication, 7: 14 - 45.

[22]. Nwaorgu OC., Okeibunor J., Madu E., Amazigo U., Onyegegbu N. and Evans, D. (1998). A school-based schistosomiasis and intestinal helminthiasis control programme in Nigeria: acceptability to community members. Tropical Medicine and International Health. 3: 842 - 849.

[23]. aiwo AK and Agbolade OM. (2000). Intestinal helminthiasis among school children in Oru, Ogun State, Nigeria. Nigerian Journal of Science, 34: 283 - 286.

[24]. Adeyeba OA and Akinlabi AM. (2002). Intestinal parasitic infections among school children in a rural community, southwest Nigeria. Nigerian Journal o Parasitology, 23: $11-18$.

[25]. kenyong EA and Eyo JE. (2008). Prevalence of Intestinal Helminths Infections among School Children in Tropical Semi Urban Communities. Animal Research International (2008) 5(1): $804-810$.

[26]. Damen JC., Lar P., Mershak P. et al., (2010). A comparative study on the prevalence of Intestinal Helminths of Dewormed and Non Dewormed Students in Rural area of North-Central Nigeria. LABMEDICINE. Vol. 41(10): 585-589.

[27]. Kirwan P, Asaolu SO, Molloy SF, Abiona TC, Jackson al, and Holland CV. (2009). Patterns of soil-transmitted helminths infection and impact of four-monthly albendazole treatments in preschool children from semi-urban communities in Nigeria: a double-blind Placebo-controlled randomised trial. BMC Infectious Diseases 2009, 9:20 doi: 10.1186/1471-2334-9-20.

[28]. Albonico M, Allen H, Chitsulo L, Engels D, Gabrielli AF, Savioli L. (2008). Controlling soil-transmitted helminthiasis in preschool-age children through preventive chemotherapy. PLoS NeglectedTropical Diseases 2008, 2(3): e126.

[29]. World Health Organization, WHO (1994) Bench aids for the diagnosis of intestinal parasites. World Health Organisation, Geneva.

[30]. Garcia L.S. (2001). Diagnostic Medical Parasitology, 4th ed. ASM Press, Washington, D.C.

[31]. Baidoo SE, Tay SCK, Obiri-Danso K, and Abruquah HH. (2010). Intestinal Helminth Infection and Anaemia during pregnancy: A Community Based Study in Ghana. Journal of Bacteriology Research Vol. 2(2): 9-13.

[32]. Sammy CK, Tayi SYG, Thomas KG. (2011). Accuracy of Diagnosis of Intestinal Helminth Parasites in a Reference Diagnostic Laboratory in the Ashanti Region of Ghana. International Journal of Parasitology Research. Vol: 3(1): 12-16.

[33]. Ugbomoiko US, Onajole AT, Edungbola LD. (2006). Prevalence and intensity of geohelminths infection in Oba-Ife Community of Osun State of Nigeria. Nigerian Journal of Parasitology Vol. 11: 62-67.

[34]. Ozumba UC., Ozumba N. (2002). Patterns of Helminth Infection in the Human Gut at the University of Nigeria Teaching Hospital, Enugu, Nigeria. J. Hlth. Sci. 48(3): 263-268.

[35]. Ekundayo, Aliyu MH., Jolly PE. (2007). A review of intestinal helminthiasis in Nigeria and the need for school-based intervention. Journal of Rural and Tropical Public Health 6: 33-39.

[36]. Akogun OB. (1989). Some social aspects of helminthiasis among the people of Gumau District, Bauchi State, Nigeria. Journal of Tropical Medicine and Hygiene 92:193-196.

[37]. Adeyeba OA. and Akinlabi AM. (2002). Intestinal parasitic infections among school children in a rural community, southwest Nigeria. Nigerian Journal o Parasitology, 23: 11-18.

[38]. Asaolu SO., Holland CV., Jegede JO, Fraser NR, Stoddard RC, Crompton DW. (1992) The prevalence and intensity of soiltransmitted helminthiases in rural communities in southern Nigeria. Annals of Tropical Medicine and Parasitology 86:279-287.

[39]. Nwosu ABC. (1981). The community ecology of soil-transmitted helminth infections of humans in a hyper endemic area of southern Nigeria. Annals of Tropical Medicine and Parasitology 75:197-203.

[40]. Adeyeba OA. and Dipeolu OO. (1984) A survey of gastrointestinal parasites in a local government area of south-west Nigeria. International Journal of Zoonoses 11:105-110.

[41]. ' 'larcain P. and Holland CV. (2000). The public health importance of Ascaris lumbricoides. Parasitology, $121: 51$ - 71.

[42]. Crompton DWT. (1994). Ascaris lumbricoides. In: Scott M. E. and Smith G. (Eds.). Parasitic and infectious diseases. Academy Press Incorporated, New York.

[43]. Narain K., Rajguru, S K. and Mahanta, J. (2000). Prevalence of Trichuris trichiura in relation to socio-economic and behavioural determinants of exposure to infection in rural Assam. Indian Journal Medical Research, 112: 140 - 146. 